Tohoku J. Exp. Med., 2006, 208, 9-17

\title{
Appearance of Abnormal Electrocorticogram Patterns during Umbilical Cord Compression in Sheep Fetus
}

\author{
Takeshi Takahashi, Junichi Sugawara, Hiroshi Chisaka, Noriaki Imai, \\ Masatoshi Saito, Takashi Murakami, Yoshitaka Kimura and \\ KUNIHIRO OKAMURA \\ Department of Obstetrics and Gynecology, Tohoku University Graduate School \\ of Medicine, Sendai, Japan
}

\begin{abstract}
Takahashi, T., Sugawara, J., Chisaka, H., Imai, N., Saito, M., Murakami, T., Kimura, Y. and Okamura, K. Appearance of Abnormal Electrocorticogram Patterns during Umbilical Cord Compression in Sheep Fetus. Tohoku J. Exp. Med., 2006, 208 (1), 9-17 — A frequent cause of fetal acidemia, which sometimes results in hypoxic-ischemic encephalopathy, is umbilical cord compression associated with uterine contraction. Using a sheep model of fetal acidemia, we examined the changes in electrocorticogram (ECoG), carotid artery blood flow, arterial blood pressure and fetal heart rate during cord compression. A characteristic burst of ECoG spikes emerged during cord compression at fetal arterial $\mathrm{pH} 7.18$ even before the $\mathrm{pH}$ went down to severe fetal acidemia (less than 7.10). The administration of a neuromuscular blocking agent to the fetus did not abolish the appearance of the spikes. These results suggest that cord compression may cause abnormal brain excitement even in the absence of severe fetal acidemia and that this abnormal excitement can lead to fetal brain dysfunction, if cord compression is repeated or prolonged. — fetal heart rate; cord compression; fetal electrocorticogram; fetal acidemia

(C) 2006 Tohoku University Medical Press
\end{abstract}

Various factors associated with perinatal morbidity such as birth asphyxia and postnatal events during neonatal intensive care may be responsible for cerebral damage in newborns. Cerebral palsy, which is a leading disorder of brain dysfunction in childhood, is much more likely to originate from prenatal than from intrapartum events. The incidence of brain damage occurred during delivery, which results in cerebral palsy, is not as high as once thought (Nelson 1988). Although only 10 to 20 percent of cases of cerebral palsy result from fetal asphyxia during delivery, fetal asphyxia, which can be identified after delivery with umbilical cord blood $\mathrm{pH}$ below 7.0 and base deficit more than $12 \mathrm{mmol} / \mathrm{mL}$, is still a significant cause of the hypoxic-ischemic encephalopathy in neonates that is highly associated with development of cerebral palsy (van den Berg et al. 1996; Sahdev et al. 1997; MacLennan 1999).

One frequent cause of fetal acidemia is repetitive umbilical cord compression coincident with uterine contraction. However, there is a lack of knowledge on how the fetal brain reacts during

Received August 3, 2005; revision accepted for publication October 8, 2005.

Correspondence: Dr. Kunihiro Okamura, Department of Obstetrics and Gynecology, Tohoku University

Graduate School of Medicine, 1-1 Seiryomachi, Aoba-ku, Sendai 980-8575, Japan.

e-mail: okamura@mail.tains.tohoku.ac.jp 
umbilical cord compression in hypoxemia without acidemia, an early stage of fetal compromise prior to development of acidemia. We designed a model of a gradually progressive acidemia in fetal sheep with use of repetitive cord compression and examined fetal brain reaction and other physiological parameters. Our hypothesis was that fetal brain would show a compensating reaction prior to development of other physiological abnormalities with diminishment of normal fetal heart rate variability due to cord compression, which is one of the reliable clinical indicators of the depression of fetal brain function.

\section{Materials ANd Methods}

The care and use of all animals involved in this study were approved by the Tohoku University Animal Care and Use Committee.

\section{Animal preparation}

Experiments were performed with 13 chronically instrumented fetal sheep (carried by ewes of mixed breed) of gestational age known to be between 118 and 130 days (term, 147 days) at time of maternal hysterotomy. Hysterotomy of each ewe was performed under general anesthesia with inhalation of isoflurane, nitrous oxide, and oxygen through an intratracheal tube. After exteriorization of the fetus, stainless-steel electrodes were embedded in the right and left occipital bones over the parietal cortex and fixed with bone cement. Polyvinyl catheters (outer diameter, $2.0 \mathrm{~mm}$; inner diameter, 1.2 $\mathrm{mm}$ ) were inserted aseptically into the fetal carotid artery and jugular vein under local anesthesia to avoid unnecessary stimulation. Fetal arterial blood pressure was measured via pressure transducer (Model P231D, Gould, Inc., Pasadena, CA, USA) with correction by intrauterine pressure. To measure carotid arterial flow volume, an ultrasonographic transit-time flow meter (T101 Transonic System Inc., Ithaca, NY, USA) was placed on the uncatheterized carotid artery. Tripolar cardioelectrodes were subcutaneously stitched bilaterally at the axilla and at the right hind leg of the fetus. An occluder with an inflatable cuff (OC-16, In Vivo Metric Inc., Healdsburg, CA, USA) was placed around the umbilical cord near the fetal abdomen. After surgical procedures on the fetus had been completed, the fetus was returned to the uterus. A polyvinyl catheter was inserted into the amniotic cavity for measurement of intrauterine pressure before closure of the uterus and abdominal wall of the ewe was done. The catheter and cables led directly out from the lateral abdominal wall of the ewe. The ewe's activity, food and water intake, and urine and feces production were assessed daily. The arterial catheter was continuously filled with heparin sodium solution $(0.1 \mathrm{IU} / \mathrm{ml})$ to maintain patency of the catheter. Antibiotics (mainly flomoxef, FMOX) were administered into the maternal vein and fetal vein daily postoperatively.

\section{Data sampling and analysis}

All studies were carried out after at least the second postoperative day. We recorded electrocorticogram (ECoG), electrocardiogram (ECG), carotid arterial blood pressure, carotid arterial blood flow volume, and amniotic pressure data continuously for $24 \mathrm{~h}$ as control data and continuously over the course of the experimental period. All data were preserved in a computer (Powerbook 3400c, Apple Inc.) and analyzed with Maclab system software (AD instrument Pty. Ltd., Castle Hill, NSW, Australia).

The procedure to develop fetal acidemia: We have previously described the procedure to develop fetal acidemia (Watanabe et al. 1992). The brief outline is as followed. The umbilical cord was compressed for $40 \mathrm{sec}$ by inflating the cuff with sterile saline infusion, followed by a release period of $80 \mathrm{sec}$. This set of procedures was repeated 15 times. We tentatively named this procedure "mild deceleration" based on the duration of deceleration in fetal heart rate. The second step consisted of a set of $60 \mathrm{sec}$ of compression followed by $60 \mathrm{sec}$ of release. These compressions was tentatively named "severe deceleration" based on the duration of the deceleration as well. We continued cord compression after the severe deceleration until fetal heart beat disappeared or fetal arterial blood $\mathrm{pH}$ fell to 7.0 or less.

\section{Blood gas analysis}

A fetal arterial blood sample of 0.3 to $0.4 \mathrm{~mL}$ was drawn before the start of experiments and immediately after the release of every fifth cord compression for real-time blood gas analysis with a blood gas analyzer (CIBA-CORNING 850, Medfield, MA, USA) at temperature correction to $39.0^{\circ} \mathrm{C}$.

\section{ECoG characterization}

ECoG interpretation was characterized by recognition of patterns based on amplitude and frequency of chart data and by spectral analysis of frequency and power using a time-frequency analysis with wavelet 
transform. Wavelet transform was applied principally according to Kimura et al. (1998). Waves in ECoG were tentatively divided into three bandwidths, $\delta(0.5-4 \mathrm{~Hz}), \theta$ (4-8 Hz), and $\alpha(8-13 \mathrm{~Hz})$, and the power in each bandwidth was calculated.

\section{Statistical analysis}

Statistical significance was determined by one-way analysis of variance (ANOVA). A $p$ value less than 0.05 was considered statistically significant.

\section{Results}

Fetal arterial blood gas values and heart rates prior to experimentation were as follows (mean \pm S.D. in each case): $\mathrm{pH}, 7.3424 \pm 0.043 ; \mathrm{PaCO}_{2}$, $36.56 \pm 6.85 \mathrm{mmHg} ; \mathrm{PaO}_{2}, 21.1 \pm 5.498 \mathrm{mmHg}$; fetal heart rate, $168 \pm 21.6$ beats per minute.
Fig. 1 shows an actual chart with data for arterial blood pressure, carotid artery flow, ECoG, and fetal heart rate during the control period, and during periods with mild deceleration in fetal heart rate (MD), severe deceleration (SD) in fetal heart rate, and severe deceleration with severe acidemia. A high voltage state (HV) and a low voltage state (LV) alternately appeared on the ECoG during the physiologically stable period without cord compressions. This period was deemed normal control. The increase in fetal arterial blood pressure continued during the compression when the fetus was not acidemic as in the mild deceleration, but as the fetus became acidemic, fetal arterial blood pressure gradually dropped during the compression period. In mild deceleration, carotid artery flow was maintained,

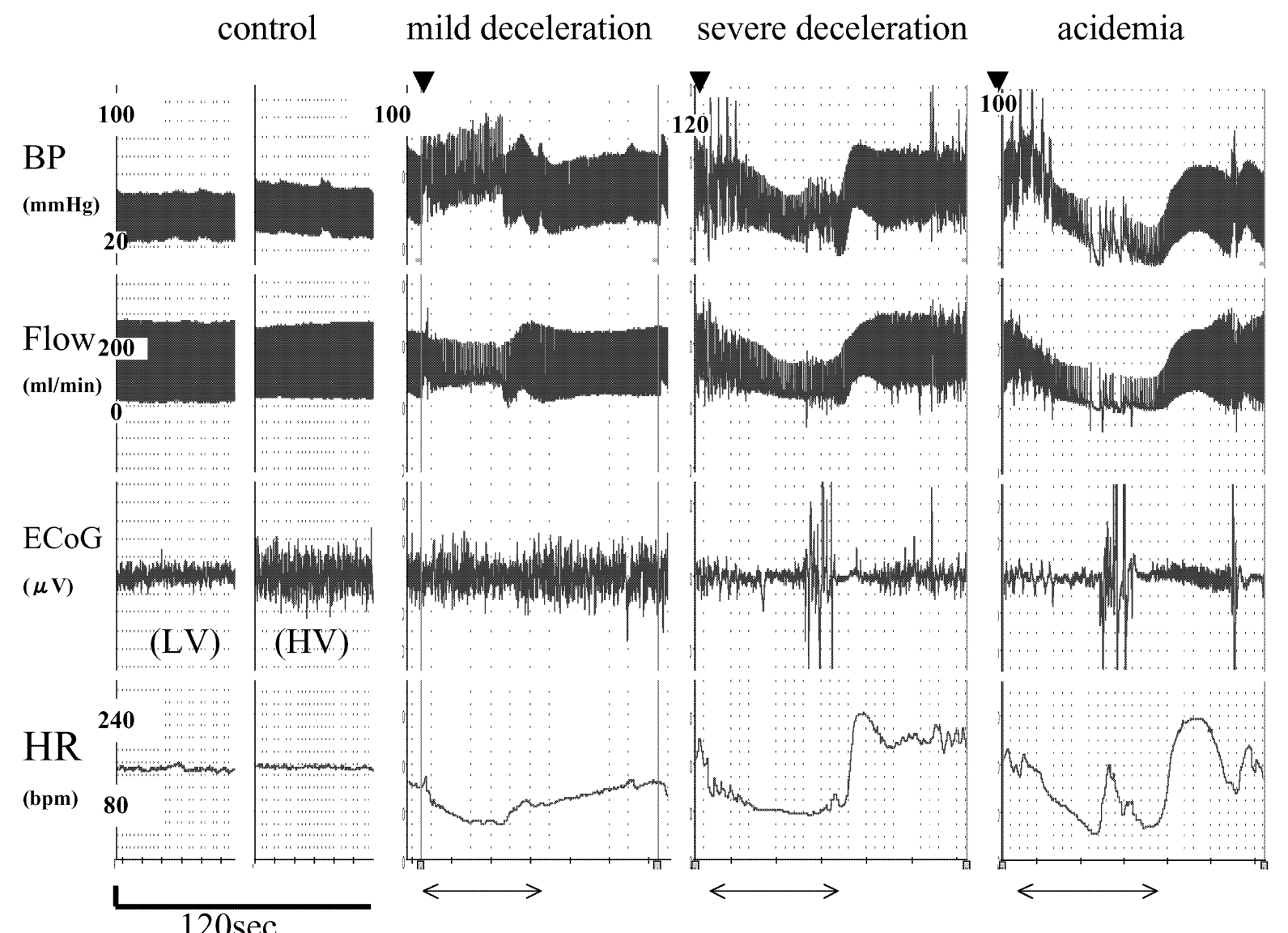

Fig. 1. Actual change of blood pressure (BP), carotid artery flow (Flow), electrocorticogram (ECoG,) and fetal heart rate (HR) during cord compression. The period of cord compression is shown as arrows $(\longleftrightarrow)$. 
but in severe deceleration it decreased during cord compression.

The change in fetal arterial blood gas values with development of acidemia is shown in Fig. 2. Acidosis gradually developed as $\mathrm{CO}_{2}$ accumulated as a result of repeated umbilical cord compression and release. Oxygen pressure remained unchanged at the point of release of each cord compression, although it decreased during each cord compression. We defined fetal acidemia as the point at which fetal arterial $\mathrm{pH}$ fell below 7.2, with severe acidemia defined by $\mathrm{pH}$ below 7.0.

During the period characterized by SD in fetal heart rate, carotid arterial blood flow volume fluctuated up and down depending on the fluctuation of blood pressure. Lactate increased with progression of acidemia, and base excess decreased (data not shown). As shown in Fig. 3, carotid arterial blood flow significantly decreased as acidemia progressed.

When an analysis of ECoG patterns was done, it became clear that $\mathrm{HV}$ emerged during MD; just after the start of SD, the HV pattern was clearly depressed, and this was followed by a characteristic burst of ECoG activity at the end of the SD phase. This burst of EcoG activity continued for several seconds during cord compression and was deemed to be spikes. In SD with acidemia fetal heart rate variability was diminished even when there was no cord compression; in this setting, EcoG spikes appeared in the middle of the SD phase coincidently with fluctuation of carotid flow (Fig. 1).

According to time-frequency analysis, fetal ECoG was roughly separated into three waves, $\delta(0.5-4 \mathrm{~Hz}), \theta(4-8 \mathrm{~Hz})$, and $\alpha(8-13 \mathrm{~Hz})$. Power decreased in all bandwidths of $\alpha, \theta$, and $\delta$ during cord compression, but it recovered after release. However, the ratio of power among the three bands during cord compression did not change as acidemia progressed.

The spikes on the ECoG recording appeared in fetal acidemia at fetal arterial blood $\mathrm{pH} 7.183 \pm$ 0.05 (range, 7.057-7.286) and appeared when carotid arterial blood flow decreased to less than $0.647 \pm 0.18$ times the control value (Fig. 4). Carotid arterial blood pressure fell significantly when spikes were seen. When we looked at fetal

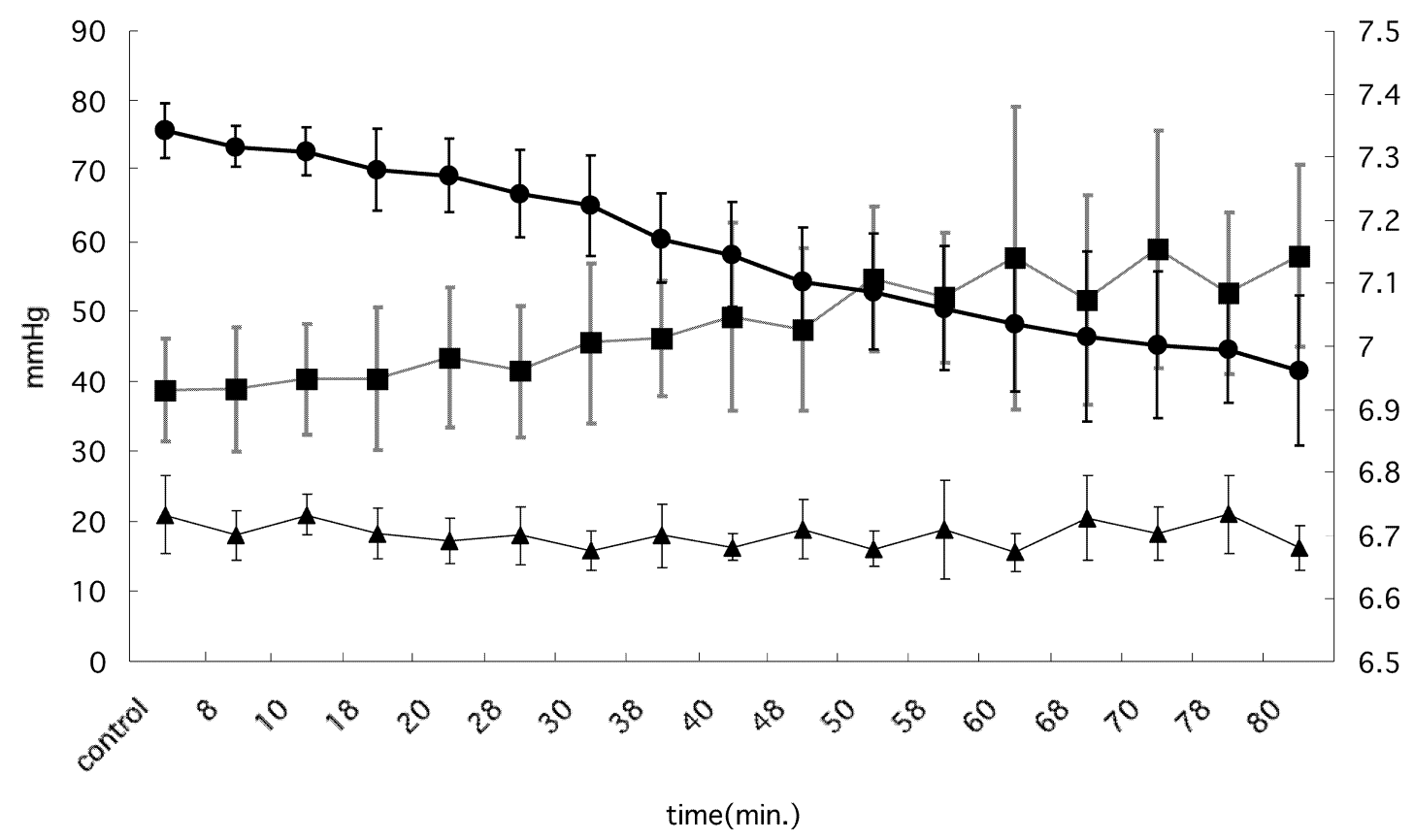

Fig. 2. Blood gas change in sheep fetus during experiment. The mild deceleration (MD) fetal heart rate pattern appeared during cord compression until $30 \mathrm{~min}$, with appearance of severe deceleration (SD) afterward. circle $(\mathbf{O}), \mathrm{pH}$; triangle $(\mathbf{\Delta}), \mathrm{PaO}_{2}$; square $(\boldsymbol{\square}), \mathrm{PaCO}_{2}$. 


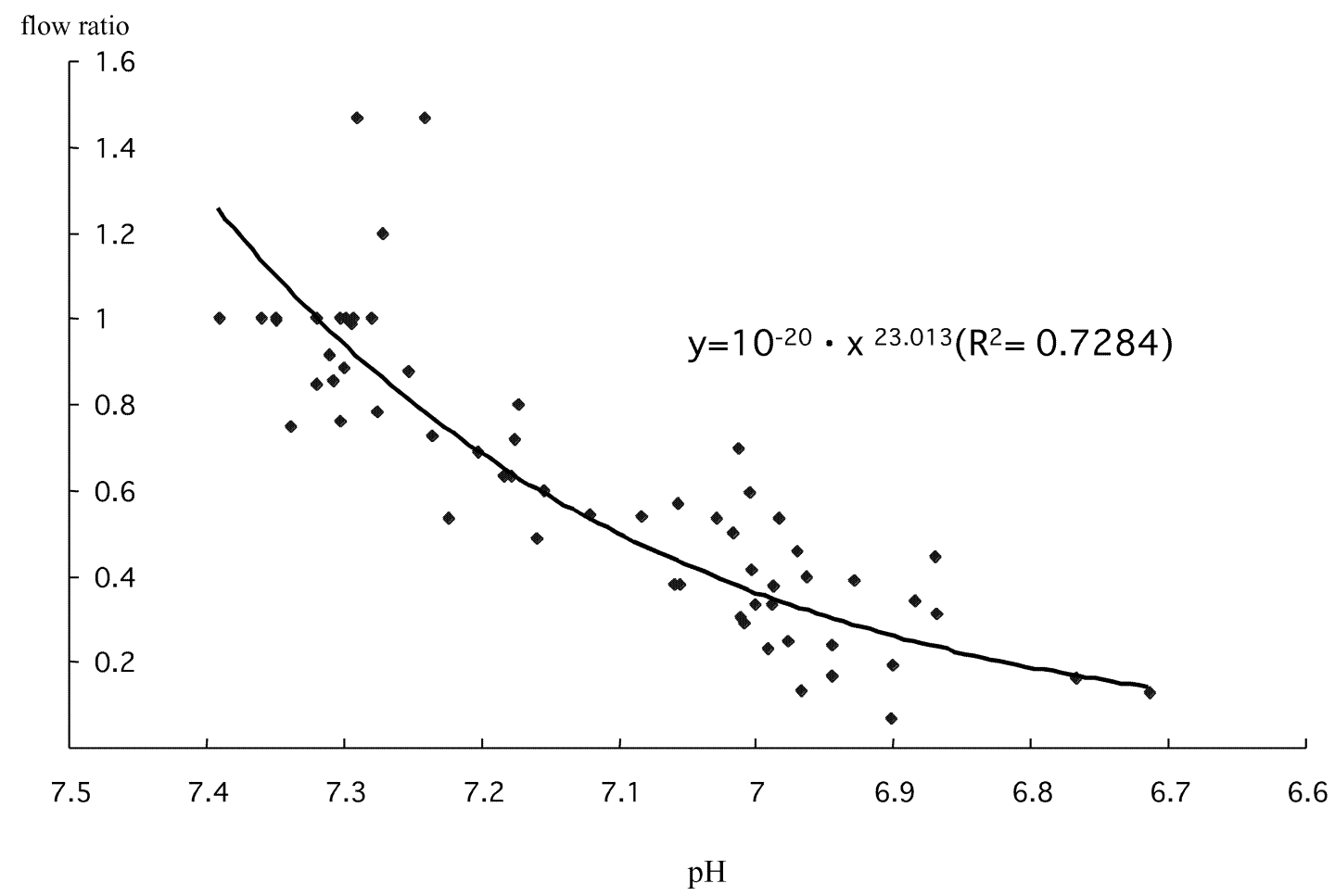

Fig. 3. Relation between carotid arterial blood flow and arterial $\mathrm{pH}$.

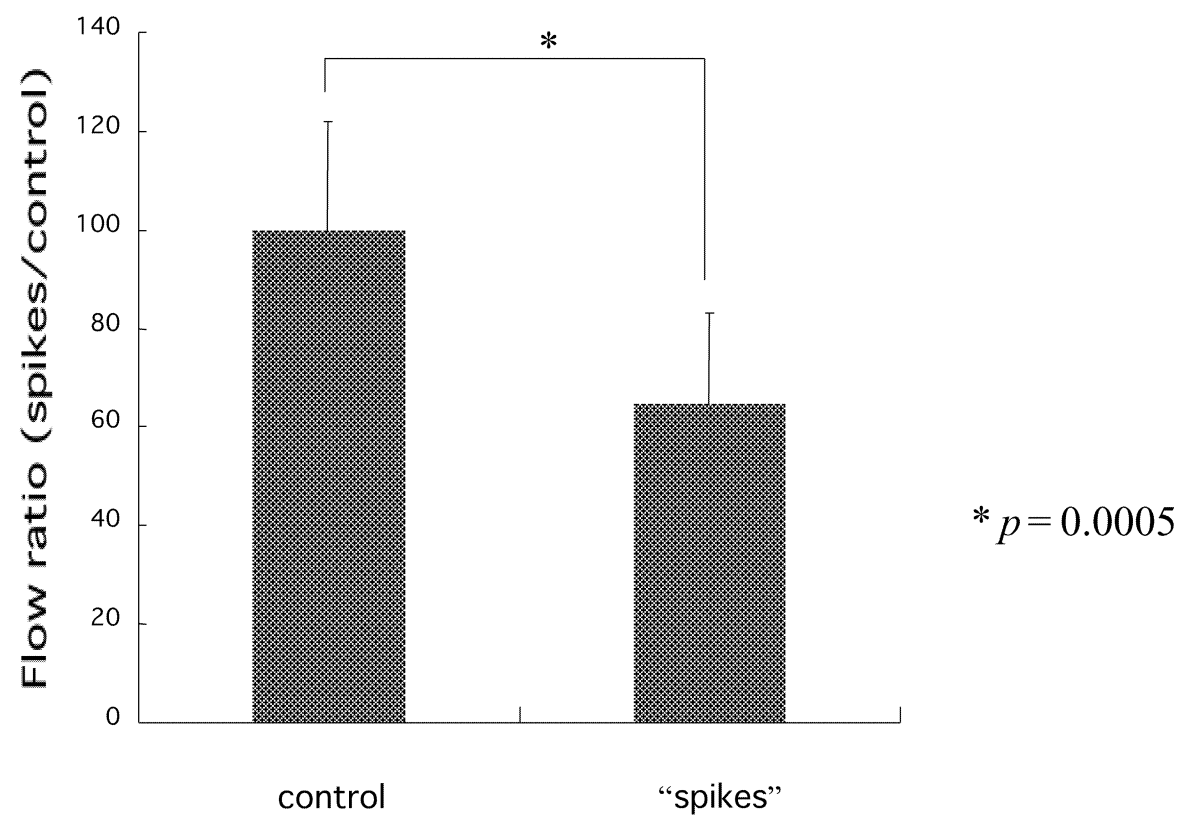

Fig. 4. Carotid arterial blood pressure fell significantly at the time of spikes in EcoG. The spikes in ECoG appeared when the decrease in carotid arterial blood flow was less than $0.647 \pm 0.18$ times control. 

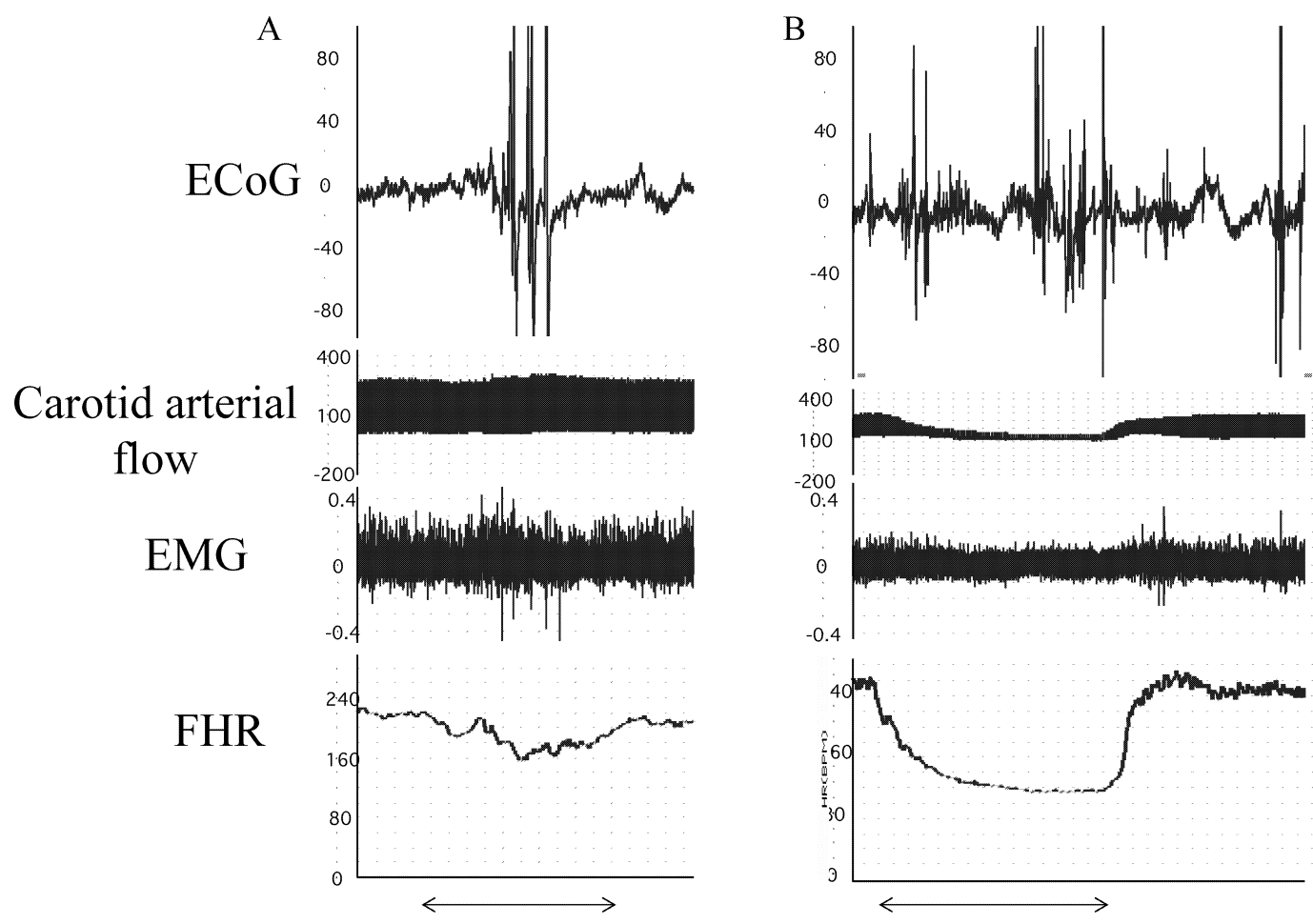

Fig. 5. Spikes are provoked in the absence of fetal movement in acidemia (B). In normal control (A), fetal movement was ascertained with electromyography at the hind leg of the fetus eliciting a highvoltage change of ECoG. ECoG, electrocorticogram; EMG, electromyogram; FHR, fetal heart rate. The period of cord compression is shown as arrows.

ECoG activity during the recovery period after the second step of cord compression, we saw that it took approximately $20 \mathrm{~min}$ until ECoG activity returned to the normal cycle of $\mathrm{HV}$ alternating with LV. In contrast, blood $\mathrm{pH}$ returned to normal in a few minutes.

In order to confirm that these changes in ECoG activity in fetal acidemia and specifically during cord compression were not provoked by fetal movement, we abolished fetal movement by administration of pancuronium bromide, which is a nondepolarizing steroidal neuromuscular blocking agent, to the fetus and recorded the ECoG during cord compression with acidemia. In the normal control state, fetal movement ascertained on electromyography of the hind leg of the fetus elicited a high-voltage change in ECoG activity, while in cord compression of a paralyzed fetus, spikes were provoked without fetal movement (Fig. 5).

\section{Discussion}

We designed a model of fetal acidemia induced by repetitive umbilical cord compressions with which we observed ECoG and other physiological parameters as fetal status changed from normal to acidemia. Under normal conditions, HV and LV states alternated in the ECoG recordings for all experimental fetal sheep. Similar observations have already been reported by others (Banford and Dawes 1990).

The present study clearly demonstrated that the fetal brain generates abnormal reactions such as extraordinary spikes in ECoG during cord compression even when there are no abnormal signs in fetal heart rate pattern such as maintenance of variability during periods without uterine contraction.

To exclude the possibility that the spikes observed in ECoG were provoked by large fetal 
movements such as fetal gasping, which is frequently observed in the most devastating stage of fetal acidemia, the fetus was paralyzed by administration of pancuronium bromide and subsequent ECoG was recorded. We recognized the characteristic spikes in the ECoG during cord compression in the status of muscle paralysis and concluded that the spikes were not elicited subsequent to fetal movement.

In our model of fetal acidemia caused by repetitive cord compression, catecholamines are released even in the early stage of stress prior to development of acidemia (Akagi et al. 1988). In the period of MD in fetal heart rate, the fetal brain should have been able to compensate for the hypoxic insult during cord compression so that brain damage was avoided. In the period of SD, in which the umbilical cord was compressed for $60 \mathrm{sec}$, fetal brains generated abnormal spikes in ECoG as they reacted to the hypoxia evident during the latter part of SD. As acidemia gradually developed, power in all bandwidths of the ECoG decreased due to an autoregulatory mechanism that limited oxygen consumption to a level low enough to compensate for hypoxic stress. Clapp et al. (1988) have reported that high amplitude ECoG or delta waves appear in fetal hypoxia. Because spikes during cord compression should be very specific, we could neither identify any characteristic change of pattern as shown by Clapp et al. (1988) nor those of hypoxic-ischemic encephalopathy (Kayser-Gathalian and Neundorfer 1980) or neonatal brain tumor (Silverman 1960), states in which substantial damage is identified.

After the period of decreased activity on ECoG, the spikes reappeared and repeated in every SD period during which fetal arterial $\mathrm{pH}$ fell below 7.2. It is not clear how the spikes in ECoG emerge during the SD period. This should be a sign of abnormal brain excitement when blood flow redistribution, which is brought about by catecholamine release, eventually collapses due to cardiac dysfunction resulting in decreased carotid blood flow. This result is quite important in showing that functionally abnormal excitement in the fetal brain should occur without recognition by conventional fetal surveillance methods such as fetal heart rate monitoring. It may also be important that all parameters in this experiment returned to normal after cessation of cord compressions.

These experimental results may have clinical implications. We should be alert when fetal heart rate decelerations occur with normal variability during a no-deceleration period because the fetal brain may respond abnormally to hypoxic insult during SD. The spikes seen in ECoG during SD in this study may be an initial sign of brain damage. Clapp et al. (1988) showed that one of the causes of cerebral damage recognized after birth may be repetitive hypoxic insult to the fetus due to cord compression during pregnancy. They emphasized the importance of repetition of hypoxic insults for neuronal damage rather than a transient large insult. While there have been many experimental reports in various species concerning hypoxic-ischemic encephalopathy, it is quite difficult to elucidate the relation between duration of hypoxia and severity of damage, or characteristic parts of the brain that are damaged. However, functional abnormality as shown in ECoG should precede any encephalopathy.

It has been demonstrated in neonate or adult study that seizure or abnormal spikes in ECoG is associated with functional defects in cerebral anomalies and encephalopathy (Silverman 1960; Kayser-Gatchalian and Neundorfer 1980; Daly and Markand 1990; Johnston et al. 1997). In this study, it is unclear whether the spikes recognized in fetal ECoG would result in brain damage, but in a period of spikes, the fetus should be cautiously monitored by various parameters and its condition should not be ignored.

We showed in our experimental system of fetal acidemia caused by repetitive cord compression that during progression of fetal acidemia, fetal heart rate pattern characteristically changes (Akagi et al. 1988), the T wave in the fetal ECG is augmented (Watanabe et al. 1992), and blood flow in various vessels changes (Okamura et al. 1992). These parameters could be helpful in clinically identifying fetal acidemia leading to irreversible central nervous system damage. In the 
present study, carotid artery blood flow decreased to $70 \%$ of control level when spikes appeared in ECoG for the first time. Because fetal arterial blood $\mathrm{pH}$ was 7.183 when carotid blood flow decreased, the spikes probably represented fetal seizure that may have been caused at least in part by brain ischemia. Considering a good correlation between carotid artery blood flow and $\mathrm{pH}$, one way to clinically screen the fetal condition associated with EcoG spikes would be measurement of fetal carotid flow by Doppler ultrasound.

In the current definition of fetal asphyxia that can lead to hypoxic-ischemic encephalopathy, umbilical arterial $\mathrm{pH}$ is required to be lower than 7.0 (Goldaber et al. 1991; Andres et al. 1999). It is well known that neonatal seizures and other morbidities, and even neonatal death, are more common in neonates with umbilical artery $\mathrm{pH}<$ 7.0 (Low et al. 1988; Thorp et al. 1989; Winkler et al. 1991; Nagel et al. 1995).

Andres et al. (1999) suggested that pathologic fetal acidemia should be $\mathrm{pH}<7.0$ in arterial blood with a metabolic component. On the other hand, several authors defined significant acidemia as the range of $\mathrm{pH}$ from 7.10 to 7.18 that is 2 standard deviations below the mean for a given population (Yeomans et al. 1985; Ruth and Raivio 1988). These reports and definitions utilize a low $\mathrm{pH}$ compared with the arterial $\mathrm{pH} 7.183$ that experimentally was associated with appearance of spikes.

We should be alert clinically when fetal heart rate deceleration occurs during pregnancy earlier than labor and delivery at term.

\section{References}

Akagi, K., Okamura, K., Endo, C., Saito, J., Tanigawara, S., Shintaku, Y., Watanabe, T., Sato, A. \& Yajima, A. (1988) The slope of the heart rate deceleration is predictive of fetal condition during repeated umbilical cord compression in sheep. Am. J. Obstet. Gynecol., 159, 516-522.

Andres, R.L., Saade, G., Gilstrap, L.C., Wilkins, I., Witlin, A., Zlatnik, F. \& Hankins, G.V. (1999) Association between umbilical blood gas parameters and neonatal morbidity and death in neonates with pathologic fetal acidemia. Am.J. Obstet. Gynecol., 181, 867-871.

Bamford, O.S. \& Dawes, G.S. (1990) Hypoxia and electrocortical activity in the fetal lamb: effects of brainstem transection and chemoreceptor denervation. J. Dev. Physiol., 13, 271-276.
Clapp, J.F., Press, N.S., Wesley, M. \& Mann, L.I. (1988) Brain damage after intermittent partial cord occlusion in chronically instrumented fetal lamb. Am. J. Obstet. Gynecol., 159, 540-549.

Daly, D.D. \& Markand, O.N. (1990) Focal brain lesions. In: Current Practice of Clinical Electroencephalography. 2nd ed., edited by D.D. Daly \& T.A. Pedley, New York: Raven Press, 45, 335-370.

Goldaber, K.G., Gilstrap, L.C., III., Leveno, K.J., Dax, J.S., McIntire, D.D. (1991) Pathologic fetal acidemia. Obstet. Gynecol., 78, 1103-1107.

Johnston, S.C., Siedenberg, R., Min, J.K., Jerome, E.H. \& Laxer, K.D. (1997) Central apnea and acute cardiac ischemia in a sheep model of epileptic sudden death. Ann. Neurol., 42, 588-594.

Kayser-Gatchalian, M.C. \& Neundorfer, B. (1980) The prognostic value of EEG ischemic cerebral infarction. Electroencephalogr. Clin. Neuro. Physiol., 49, 608-617.

Kimura, Y., Okamura, K., Watanabe, T., Yaegashi, N., Uehara, S. \& Yajima, A. (1998) Time-frequency analysis of fetal heartbeat fluctuation using wavelet transform. Am. J. Physiol., 275, H1993-H1999.

Low, J.A., Galbraith, R.S., Muir, D.W., Killen, H.L., Pater, E.A. \& Karchmar, E.J. (1988) Motor and cognitive deficits after intrapartum asphyxia in the mature fetus. Am. J. Obstet. Gynecol., 158, 356-361.

MacLennan, A. (1999) A template for defining a causal relation between acute intrapartum events and cerebral palsy: international consensus statement. Br. Med. J., 319, 1054-1059.

Nagel, H.T., Vandenbussche, F.P., Oepkes, D., JennekensSchinkel, A., Laan, L.A. \& Gravenhorst, J.B. (1995) Follow-up of children born with an umbilical arterial blood $\mathrm{pH}<7$. Am. J. Obstet. Gynecol., 173, 1758-1764.

Nelson, K.B. (1988) What proportion of cerebral palsy is related to birth asphyxia? J. Pediatr., 112, 572-574.

Okamura, K., Shintaku, Y., Watanabe, T., Tanigawara, S., Endo, H., Akagi, K. \& Yajima, A. (1992) Femoral artery blood flow monitoring has distinct advantages for examining redistribution of blood flow in fetal acidosis. J. Perinat. Med., 20, 215-222.

Ruth, V.J. \& Raivio, K.O. (1988) Perinatal brain damage: predictive value of metabolic acidosis and the Apgar score. Br. Med. J., 297, 24-27.

Sehdev, H.M., Stamilio, D.M., Macones, G.A., Graham, E. \& Morgan, M.A. (1997) Predictive factors for neonatal morbidity in neonates with in umbilical arterial cord $\mathrm{pH}$ less than 7.00. Am. J. Obstet. Gynecol., 177, 1030-1034.

Silverman, D. (1960) Serial electroencephalography in brain tumors and cerebrovascular accidents. Arch. Neurol., 2, $122-129$.

Thorp, J.A., Sampson, J.E., Parisi, V.M. \& Creasy, R.K. (1989) Routine umbilical cord blood gas determinations. Am. J. Obstet. Gynecol., 161, 600-605.

van den Berg, P.P., Nelen, W.L., Jongsma, H.W., Nijland, R., Kollee, L.A., Nijhuis, J.G. \& Eskes, T.K. (1996) Neonatal complications in newborns with an umbilical artery $\mathrm{pH}<$ 7.00. Am. J. Obstet. Gynecol., 175, 1152-1157.

Watanabe, T., Okamura, K., Tanigawara, S., Shintaku, Y., Aakagi, K., Endo, H. \& Yajima, A. (1992) Change in electrocardiogram T-wave amplitude during umbilical cord compression is predictive of fetal condition in sheep. Am.J. Obstet. Gynecol., 166, 246-255.

Winkler, C.L., Hauth, J.C., Tucker, J.M., Owen, J. \& Brumfield, C.G. (1991) Neonatal complications at term as related to 
the degree of umbilical artery acidemia. Am. J. Obstet. Gynecol., 164, 637-641.

Yeomans, E.R., Hauth, J.C., Gilstrap, L.C., III. \& Strickland,
D.M. (1985) Umbilical cord pH, $\mathrm{PCO} 2$, and bicarbonate following uncomplicated term vaginal deliveries. Am. J. Obstet. Gynecol., 15, 798-800. 